\title{
À flor da pele
}

Isabel Santos*, Catarina Empis*

\author{
A pele cobre tudo \\ Pele de veludo \\ Pele é a roupa natural \\ (e a mais legal) \\ A pele nela revela quem vocêé \\ Da ponta da cabeça \\ Até à pele da ponta do pél (Jair de Oliveira)
}

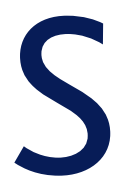

ão frequentes as referências à pele de cantores, escultores, escritores, pintores. Barthes disse que «a linguagem era como uma pele: com ela entro em contacto com os outros $»^{2}$. Por isso, a utilizamos em tantas metáforas quando comunicamos. Esta aparece em muitas expressões de avaliação sempre que queremos exprimir sentimentos fortes («quem foi que à tua pele conferiu esse papel de mais que tua pele ser pele da minha pele ${ }^{3}$ ?»), conflitos insanáveis (não me dou com fulano ou sicrano é uma questão de pele). O nosso discurso e pensamento, a linguagem dos dias, "a pele engelhada do quotidiano»" é pontuada por metáforas positivas e negativas sobre este invólucro que enclausura e delimita, importante órgão dos nossos sentidos, de protecção, de defesa e de transformação.

A pele é rica e multifacetada. Antes de mais nada, é dotada de uma opulência de terminais nervosos que a torna um importante órgão sensorial, fonte do primeiro dos nossos cinco sentidos - o tacto. Ou seja, joga na equipa do olho, do ouvido, da língua e do nariz. Mas essa é a menor de todas as suas virtudes. A pele protege-nos contra agressões químicas e físicas, age como um filtro permitindo uma infinidade de mutações biológicas, sintetizando vitaminas essenciais ao crescimento, além da calcificação dos ossos. E, finalmente, os vasos sanguíneos que a cobrem mantêm a nossa temperatura constante e permitem o processo de exalação de partículas líquidas, através dos poros, a transpiração. Resumindo, a pele protege, metaboliza, harmoniza, informa.

*Editora da RPCG.
Ter uma pele saudável é tão importante como ter qualquer outro órgão ou parte do corpo saudável. Nem todos, médicos e cidadãos, reconhecem a sua importância para a saúde geral e, por isso, muitas das suas alterações decorrem de agressões diversas ao longo do tempo sem que ninguém lhe preste muita atenção. A pele tem vários inimigos. Talvez o pior deles seja a moda. Ninguém está feliz com a pele que tem e acham que ela, como qualquer peça de vestuário, pode ser tingida, esticada, alinhavada, trocada e estorricada ao sol, com cremes ou através de raios ultravioleta.

Aproximadamente um quarto da população é afectado por problemas da pele que beneficiariam com cuidados médicos. A maioria dos problemas é atendida e gerida nos cuidados de saúde primários. No entanto, assiste-se a pouca discussão de casos no desenvolvimento profissional contínuo, sendo que existem diversas alusões à referenciação inadequada a dermatologistas. $\mathrm{O}$ exame e o diagnóstico de lesões na pele são frequentemente sinónimo de confusão e mistério para muitos médicos. Mesmo os que possuem boas e precisas capacidades de diagnóstico em muitas outras áreas é frequente sentirem-se perdidos quando confrontados com um simples exantema.

O desafio ao examinar a pele reside em distinguir o normal do anormal, os dados significativos dos triviais, e integrar os sinais e sintomas pertinentes num diagnóstico diferencial apropriado. $\mathrm{O}$ facto de a pele ser $\mathrm{o}$ maior órgão humano é uma vantagem e uma desvantagem. É uma vantagem porque não precisamos de instrumentos especiais e porque a pele pode ser biopsada com pouca morbilidade. Contudo o observador casual pode ser enganado por uma variedade de estímulos.

As doenças da pele são motivo de consulta em cerca de 10 a $15 \%$ das consultas de medicina geral e familiar. A percentagem destes motivos é variável com os locais de exercício variando entre $3 \%$ a $18,8 \%$, com uma média de $8,4 \% .^{5,6,7}$ Para se providenciarem cuidados apropriados seria necessário que periodicamente avaliássemos o tipo de trabalho que nesta área fazemos e 
as mudanças nos números e na tipologia de referenciação. Acresce dizer que a referenciação a esta especialidade é particularmente difícil possivelmente porque muitos dos problemas enviados poderiam ser tratados no âmbito da nossa disciplina. Daí a razão de ser deste dossier.

Procurámos trazer temas do dia-a-dia do médico de família e na forma como se nos apresentam. Pedimos expressamente a cada autor que procurasse, para além da necessária revisão e integração do tema, responder a algumas das questões que se nos levantam no exercício diário da nossa prática.

Dos fungos $^{8}$, que não escolhem género nem idade, tão ubíquos e diversos nas suas localizações e apresentações, ao acne ${ }^{9,10}$ que tanto desfeia e preocupa os adolescentes, que não se cansam de se olhar ao espelho e procurar um ponto aqui, mais outro ali e ainda outro acolá, somando-se em quantidade e subtraindo-lhes em auto-estima.

E porque, para além da imagem exterior é muito incómoda a sensação da coceira que não passa, não pára, não deixa dormir, não deixa descansar, não podiam faltar aqui o eczema ${ }^{11}$ atópico e a urticária ${ }^{12}$.

Esperamos, com este dossier, contribuir para que os problemas da pele possam passar a ser um mal menor para os nossos doentes e que, assim, os possamos ajudar a sentirem-se sempre bem na sua pele, a tal que "nela revela quem vocêe da ponta da cabeça, até à pele da ponta do pé".

\section{REFÊRENCIAS BIBLIOGRÁFICAS}

1. Jair de Oliveira. Disponível em: http://letras.terra.com.br/jairoliveira/820115/ [acedido em 20/02/2011].

2. Roland Barthes Fragments $d$ un discours amoureux; 1977. Disponível em: http://www.dico-citations.com/le-langage-est-une-peau-je-frottemon-langage-contre-l-autre-barthes-roland [acedido em 20/02/2011].

3. David Mourão Ferreira. Disponível em: http://pt.weblog.com.pt/arqui- vo/cat_david_mourao_ferreira.html [acedido em 20/02/2011].

4. Virginia Woolf. Disponível em: http://www.citador.pt/citacoes.php? cit $=1 \& o p=7 \&$ author $=254 \&$ firstrec $=0$ [acedido em 20/02/2011].

5. Royal College of General Practitioners. Training in Dermatology for General Practice Taskforce. Learning General Practice Dermatology. London: RCGP; 2000.

6. Williams HC. Increasing demand for dermatological services: how much is needed? J R Coll Physicians Lond 1997 May-Jun: 31 (3): 261-2.

7. Verhoeven EW, Kraaimaat FW, van Weel C, van de Kerkhof PC, Duller $P$, van der Valk PG, et al. Skin diseases in family medicine: prevalence and health care use. Ann Fam Med 2008 Jul-Aug; 6 (4): 349-54.

8. DermNet NZ. Prevalence of skin diseases. Disponivel em http://www.dermnetnz.org/doctors/principles/prevalence.html [acedido em 20/02/2011].

9. Royal College of General Practitioners. Training in Dermatology for General Practice. Morbidity Statistics from General Practice Fourth National Study 1991-2. London: RCGP; 1995.

10. Tomaz D. Será fungo? Rev Port Clin Geral 2011 Jan-Fev; 27 (1): 96-108.

11. Figueiredo A, Massa A, Picoto A, Soares AP, Basto AS, Lopes C, et al. Avaliação e tratamento do doente com Acne - Parte I: epidemiologia, etiopatogenia, clínica, classificação, impacto psicossocial, mitos e realidades, diagnóstico diferencial e estudos complementares, Rev Port Clin Geral 2011 Jan-Fev; 27 (1): 59-65.

12. Figueiredo A, Massa A, Picoto A, Soares AP, Basto AS, Lopes C, et al.Avaliação e tartamento do doente com Acne - Parte II:Tratamento tópico, sistémico e cirúrgico; tratamento da acne na grávida, algoritmo terapêutico. Rev Port Clin Geral 2011 Jan-Fev; 27 (1): 66-76.

13. Claro C. Eczema atópico na criança e no adulto. Rev Port Clin Geral 2011 Jan-Fev; 27 (1): 78-82.

14. Chambel M,Antunes J, Prates S. O mundo da urticária, com e sem alergia, Rev Port Clin Geral 2011 Jan-Fev; 27 (1): 84-94.

\section{CONFLITOS DE INTERESSES}

As autoras declaram não possuir conflitos de interesse.

\section{ENDEREÇO PARA CORRESPONDÊNCIA}

Departamento de Medicina Geral e Familiar

Faculdade de Ciências Médicas de Lisboa,

Campo dos Mártires da Pátria, 130, 1169-056 Lisboa

E-mail: isabel.santos@fcm.unl.pt

Recebido em 10/02/2011

Aceite para publicação em 15/02/2011 